\title{
KEKERASAN, BALAS DENDAM, DAN PENGAMBING HITAMAN DALAM TIGA CERPEN INDONESIA
}

Violence, Revenge, and Scapegoating in Three Indonesian Short Stories

\section{Novita Dewi}

Universitas Sanata Dharma

Pos-el: novitadewi@usd.ac.id

Naskah diterima: 29 September 2019; direvisi: 19 Juni 2020 ; disetujui: 24 Juni 2020

DOI: $10.26499 /$ jentera.v9i1.1755

\begin{abstract}
Abstrak
Tujuan penelitian ini adalah mengamati representasi kekerasan, balas dendam, dan pengambinghitaman dalam tiga cerpen Indonesia, yaitu "Kuli Kontrak" karya Mochtar Lubis, "Tukang Cukur" karya Budi Darma, dan "Akhir Perjalanan Gozo Yoshimasu" karya Sori Siregar. Metode content analysis digunakan dalam penelitian ini dengan terang teori hasrat mimesis dan kambing hitam dari René Girard. Penelitian ini menghasilkan tiga temuan. Pertama, kekerasan sebagai buntut hasrat mimesis dapat terjadi antarindividu, inividu terhadap kelompok, dan kelompok terhadap individu. Kekerasan bersifat menular serta menyebar dengan cepat. Kedua, aksi balas dendam yang merupakan dampak langsung rivalitas dalam ketiga cerpen terjadi atas nama perempuan, kucuran darah, dan kekuasaan. Dari ketiga hal tersebut yang paling korosif adalah kekuasaan. Ketiga, mekanisme kambing hitam pada ketiga cerpen memiliki penyebab dan siratan yang berbeda-beda, sedangkan persamaannya adalah kambing hitam mewujud dalam diri tokoh-tokoh yang kalah dan terpinggirkan. Mereka dikorbankan untuk memutus rantai kekerasan sehingga dapat membawa perdamaian.
\end{abstract}

Kata-kata kunci: balas dendam, kambing hitam, kekerasan, hasrat

\section{Abstract}

This study aims to investigate the representation of violence, revenge, and scapegoating in three Indonesian short stories, i.e. "Kuli Kontrak" [The Contract Coolie] by Mochtar Lubis, "Tukang Cukur" [The Barber] by Budi Darma, and "Akhir Perjalanan Gozo Yoshimasu” [The End of Gozo Yoshimasu's Journey] by Sori Siregar. Content analysis method is applied to read the short stories in light of René Girard's theory of mimetic desire and sacpegoating. The study reveals that first, violence as repercussion of mimetic desires and rivalry can occur between individuals, individuals to groups, and groups to individuals; and violence is contagious and spreads quickly. Second, revenge which is a direct impact of rivalry in the three short stories takes place on behalf of women, bloodshed, and power; and the most corrosive is power. Third, the scapegoat mechanism in these short stories has different causes and implications; while the similarity is that the scapegoat manifests in the defeated and marginalized personas. They are sacrificed to break the chains of violence and to bring peace.

Keywords: revenge, scapegoating, violence, desire

How to Cite: Novita Dewi. (2020). Kekerasan, Balas Dendam, dan Pengambing Hitaman Dalam Tiga Cerpen Indonesia. Jentera: Jurnal Kajian Sastra, 9(1), 43-58. doi: 10.26499/jentera.v9i1.1755 
Kekerasan, Balas Dendam, dan Pengambing Hitaman...

\section{PENDAHULUAN}

Balas dendam selalu mewarnai karya sastra di seluruh penjuru dunia dari waktu ke waktu, baik karya yang klasik maupun kontemporer. Dalam drama Shakespeare, misalnya, Hamlet menuntut balas atas kematian ayahnya pada Claudius, sang paman yang menikahi ibunya. Gertrude, ibu Hamlet, minum dari cawan mematikan yang diperuntukkan bagi putranya yang terluka parah oleh Laertes, calon ipar Hamlet, sebagai pembalasan atas kematian ayah dan saudara perempuannya.

Contoh kedua diambil dari tanah air sendiri. Menurut kitab Pararaton, terdapat setidaknya enam orang yang terbunuh oleh keris Empu Gandring. Setelah membunuh si pembuat keris, Ken Arok menghabisi nyawa Tunggul Ametung dengan keris itu, lalu menikahi istrinya, Ken Dedes. Ken Arok dibunuh oleh anak Ken Dedes, Anusapati, dengan keris yang sama, kemudian si pembunuh naik takhta. Lalu, Anusapati dibunuh oleh Tohjaya, anak Ken Arok dari selir Ken Umang. Tohjaya akhirnya tewas dalam pemberontakan yang dipimpin oleh Ranggawuni, anak Anusapati.

Untuk menambah deretan narasi balas dendam, sastra dan budaya populer juga sarat dengan aksi rivalitas dan kekerasan. Pentas gladiator di Kota Panem menjadikan aksi bunuh-membunuh sebagai tontonan dalam film "The Hunger Games" yang diadaptasi dari novel Suzanne Collins yang berjudul sama. Fiksi distopia itu menggambarkan bahwa manusia berpotensi menghancurkan diri sendiri dan sesamanya atas nama hasrat, persaingan, dan dendam kesumat.

Kajian tentang kekerasan dan balas dendam dalam sastra Indonesia sudah banyak dilakukan, misalnya Thahar (2008); Ferdinal, McCredden, Coté, \& Clark (2013); dan Prasetyo \& Haryadi (2017). Namun, hadirnya korban dalam relasi kekerasan dan balas dendam yang digambarkan dalam sastra tanah air belum cukup memadai.

Meskipun awalnya dapat membawa kelegaan, balas dendam bersifat merusak dan mengubah si korban menjadi sama kejam dengan sang penyerang sehingga rantai kekerasan itu hanya bisa diputus oleh pengampunan. Pengampunan tumbuh dari kemampuan seseorang untuk mengubah dorongan membalas dendam menjadi pencarian makna yang lebih besar. Oleh sebab itu, semacam "tumbal" diperlukan untuk menyudahi kaitan yang beruntun antara kekerasan dan balas dendam, yaitu dengan cara pengambinghitaman. Pihak ketiga dibutuhkan untuk menghentikan siklus kekejaman dan balas dendam yang terus berlanjut. 
Melalui penelitian ini dicermati imajinasi kekerasan, balas dendam, dan pengambinghitaman dalam tiga cerita pendek Indonesia modern dengan tiga latar belakang sejarah yang berbeda di Indonesia. Cerpen Mochtar Lubis berjudul "Kuli Kontrak" berlatar sejarah zaman kolonial di Sumatra. Cerpen "Tukang Cukur" oleh Budi Darma melintasi perjalanan sejarah bangsa dari masa penjajahan Belanda, zaman kemerdekaan, sampai era pascakolonial Indonesia. Peralihan kekuasaan dari pemerintahan Jepang ke Republik Indonesia menjadi latar cerpen “Akhir Perjalanan Gozo Yoshimasu” karya Sori Siregar.

Tujuan penelitian ini adalah untuk melihat apakah terdapat perbedaan dan persamaan dalam paparan kekerasan, balas dendam, dan pengambinghitaman dalam ketiga cerpen tersebut. Ringkasan setiap cerita berikut ini disajikan secara singkat untuk mempermudah pembahasan.

Dalam "Kuli Kontrak" dikisahkan seorang pengawas kebun (opzichter) Belanda yang diserang oleh kuli-kuli kontrak pribumi di daerah sekitar Kabupaten Kerinci, Provinsi Jambi, Sumatra Barat, pada masa kolonial. Dengan bantuan seorang pegawai pemerintah, yaitu ayah si pencerita, polisi dapat menangkap tiga orang kuli kontrak yang melawan opzichter. Para kuli marah karena si opzichter sering mengganggu istri-istri mereka. Lalu, para kuli itu pun beramai-ramai menyerangnya dan menikamnya. Ketiga kuli tersebut kemudian dijatuhi hukuman cambuk. Aksi kekerasan dan balas dendam itu disaksikan oleh si bocah pencerita yang diam-diam mengintip dari atas sebuah pohon yang tumbuh di balik tembok penjara.

Cerpen kedua yang berjudul "Tukang Cukur" dituturkan oleh seorang murid SD bernama Gito yang berjalan kaki ke sekolah hingga menemui bermacam peristiwa mengejutkan. Di desa Getas Pejaten, di pinggiran Kota Kudus, Jawa Tengah, Gito menyaksikan kebengisan seorang tukang cukur yang mengepalai pembantaian penduduk setiap kali terjadi pergantian kekuasaan. Pada September 1948 tukang cukur membela tentara PKI yang melawan tentara pemerintah. Ketika pasukan Siliwangi masuk ke Kota Kudus, tukang cukur menyamar sebagai preman yang membantu tentara dari Jawa Barat itu menghabisi orang-orang PKI. Ketika diketahui bahwa tukang cukur membuat daftar orang-orang yang tak disukainya untuk dibunuh, pasukan Siliwangi menghajarnya habishabisan. Setelah itu, tak terdengar lagi ke mana perginya si tukang cukur. Ketika tentara Siliwangi meninggalkan Kudus untuk mengejar tentara PKI yang makin terdesak ke timur, militer Belanda melakukan agresi di Kota Kudus dan tukang cukur menjadi sopir dan kaki tangan Belanda bersama Ruslan, sahabatnya. Pada Desember 1949 tentara Belanda ditarik 
Kekerasan, Balas Dendam, dan Pengambing Hitaman...

mundur dari Indonesia, lalu Tentara Nasional Indonesia (TNI) masuk ke Kota Kudus. Setelah itu, tukang cukur dan Ruslan menghilang lagi. Tidak lama kemudian, terjadi bentrokan hebat antara TNI dan tentara liar yang tergabung dalam Negara Islam Indonesia (NII). Sebagian besar tentara liar tewas terjebak di bekas pabrik rokok Nitisemito. Gito mengenali salah satunya adalah mayat si tukang cukur.

Dalam cerpen ketiga, “Akhir Perjalanan Gozo Yoshimasu”, dikisahkan nasib Kapten Gozo Yoshimasu setelah Jepang menyatakan takluk kepada Tentara Sekutu dalam Perang Dunia II. Puluhan pemuda Indonesia bersenjata bambu runcing mendatangi markas militer Jepang untuk merampas persenjataan. Perwira Jepang itu dengan halus menolak karena yang berhak melucuti mereka adalah pihak Sekutu. Untuk menghindari pertumpahan darah, Yoshimasu akhirnya mengizinkan mereka untuk mengambil semua persenjataan di markasnya. Saat itulah Yoshimasu ditikam oleh salah seorang pemuda yang kalap hingga tewas. Semua anak buahnya diseret keluar dari markas menuju ke tengah-tengah kota. Tentara-tentara Jepang yang telah dilumpuhkan itu pun diberondong satu per satu di hadapan penduduk yang berdatangan menonton. Kisah sedih itu diceritakan oleh pemimpin pasukan bambu runcing 20 tahun kemudian kepada anaknya. Dia menyesal seumur hidup karena gagal melerai anak buahnya yang brutal di markas tentara Jepang waktu itu. Dengan tekad bulat dia hendak menceritakan kepada cucu Yoshimasu yang akan datang ke Indonesia untuk mencari makam kakeknya yang tidak pernah ada.

Ketiga cerita pendek di atas memperlihatkan beberapa unsur yang sama: (1) hasrat untuk berkuasa atau memiliki sesuatu; (2) rivalitas dalam memperebutkan objek yang diinginkan; (3) kekejaman yang lahir dari situ; (4) balas dendam yang menjadi akibatnya; dan (5) mekanisme kambing hitam untuk meredam aksi kekerasan yang ada.

Dengan mempertimbangkan kesamaan unsur-unsur tersebut, teori René Girard dapat diterapkan dalam penelitian ini. Teori tersebut membantu menjelaskan bagaimana kekerasan, balas dendam, dan kambing hitam menjadi tema berulang yang mudah ditemukan dalam sastra Indonesia dari masa ke masa (lihat, misalnya, Purnawijayanti [2006] dan Dewi [2019]). Sejauh ini kajian terdahulu belum memakai Teori Girard untuk mengkaji ketiga pengarang dan karya-karya yang diteliti dalam studi ini.

Di antara ketiga pengarang tersebut, Budi Darma misalnya, paling banyak dibahas (lihat Siswanto [2010]; Suwondo [2010]; dan Nurfadila [2018]). Namun, pembahasan cerpen "Tukang Cukur" belum ditemukan. Sementara itu, sejumlah kajian memang membahas novel-novel terkenal Mochtar Lubis, seperti Alimun (2014); Andayani, \& 
Jupriono (2018); dan Suprapto (2019), tetapi tidak banyak yang mengkaji cerpencerpennya. Pembahasan terperinci tentang karya Sori Siregar hampir tidak ada, kecuali yang dilakukan bersama dengan sejumlah karya cerpenis lainnya. Oleh karena itu, kajian ini diharapkan dapat memberikan sumbangan dalam pemahaman tentang sastrawan dan dunianya.

\section{LANDASAN TEORI}

Teori René Girard dimulai dengan konsep hasrat yang merupakan landasan sifat dan perilaku manusia. Teori tersebut dapat dijelaskan secara sederhana. Sebagai contoh, dalam keadan perut kosong, seseorang akan mengirimkan sinyal lapar ke otak bahwa ia hendak makan. Akan tetapi, ada kemungkinan bahwa keinginan tersebut sebenarnya dimediasi oleh sebuah iklan makanan yang mengundang rasa lapar. Dengan demikian, keinginan manusia tidak selalu alamiah dan berasal dari internal. Setiap orang memiliki kecenderungan untuk meniru keinginan orang lain. Ia menginginkan apa yang diinginkan oleh pihak lain. Girard menyebutnya mimetic desire, yaitu keinginan mimesis atau keinginan tiruan. Karena orang saling meniru dalam hal keinginan, dapat dipastikan banyak orang memiliki keinginan yang sama. Karena menginginkan hal yang sama, dengan mudah mereka menjadi saingan satu dengan yang lainnya.

Sejumlah sastrawan besar dunia seperti Dostoevsky, Flaubert, Proust, Stendhal, dan Cervantes menjadi subjek penelitian Girard yang menjadi dasar bagi penulisan bukunya Deceit, Desire, and Novel yang terbit pada tahun 1961. Tokoh utama dalam novel-novel besar yang dipelajari oleh Girard memperjuangkan objek hasrat yang sama, misalnya perempuan, kekuasaan, dan kekayaan. Sedemikian sengitnya persaingan antartokoh itu sehingga mereka saling cemburu satu dengan yang lainnya.

Dalam bukunya The Scapegoat (1986), Girard melakukan pembacaan kritis atas sejumlah tokoh fiksi dan menemukan bahwa hasrat dan persaingan (keduanya mimesis) yang ditunjukkan oleh setiap tokoh tadi menghasilkan ketegangan sosial atau kekerasan. Menurut Girad, hasrat mengandung potensi konflik karena sifat dan watak mimesisnya. Jika rivalitas berkembang dari persaingan antarindividu menjadi konflik sosial, lahirlah kekerasan yang dimobilisasi (Girard, 1986, p. 16). Kekerasan semacam itu tidak terhindarkan sehingga membutuhkan adanya pengambinghitaman. Girard menjelaskan mekanisme kambing hitam secara panjang lebar dengan cara meminjam contoh sejumlah tokoh yang diambil dari berbagai sumber, seperti mitologi, sastra, dan Alkitab. 
Kekerasan, Balas Dendam, dan Pengambing Hitaman...

Menurut sejarawan dan filsuf Prancis tersebut, pengambinghitaman akan efektif jika hubungan antarmanusia terpecah seiring dengan merebaknya bencana alam, seperti kekeringan, gempa bumi, dan epidemik. Baik dalam mitologi maupun wacana pada zaman modern, pengorbanan diperlukan untuk menghambat konflik dan terjadinya kekacauan yang lebih dahsyat. Penelitian Girard tentang hasrat dan kekerasan pada pelbagai tokoh dalam mitos dan Alkitab berkontribusi pada teori filsafat, teologi, sastra, antropologi, dan ilmu pengetahuan manusia kontemporer lainnya (Abshire, 2010; Schwager, 2000).

Teori Girard membongkar diskursus hewan kurban dalam agama-agama besar. Budaya, termasuk juga agama, adalah institusi manusia yang dibayang-bayangi oleh hasrat, persaingan, dan kekerasan sehingga bermuara pada pembunuhan kambing hitam. Jika semula kambing hitam dianggap sebagai penyebab terjadinya kekerasan, kini disakralkan sehingga lahirlah kekerasan sakral seperti terlihat pada praktik ritual (Schwager, 2000).

Interpretasi dan pembacaan reflektif-kontekstual atas teori Girard dirangkum oleh Sindhunata dalam karyanya yang berjudul Kambing Hitam: Teori René Girard (Sindhunata, 2006). Menurut Sindhunata, perjalanan intelektual Girard menuntun ilmuwan Prancis yang hijrah ke Amerika itu menuju kepada pertobatannya. Kebangkitan diri dialami oleh Girard yang semula hidup sebagai agnostik itu. Pemikir besar abad ke20 itu pun memeluk kembali agama yang diyakininya dengan penuh sukacita (Sindhunata, 2006: 8). Girard mengupas tuntas agama beserta mitos dan ritualnya. Dengan ritual, krisis mimesis dipatahkan. Ritus korban merupakan tindakan kekerasan yang memungkinkan diakhirinya risiko balas dendam. Karena itu, menurut Girard, agama tidak identik dengan kekerasan, tetapi justru mengajarkan bagaimana mengelola, mengendalikan, dan mengurangi kekerasan. Tepatlah kata Sindhunata bahwa "Girard memang merupakan apologetisme agama dalam zaman modern" (Sindhunata, 2006: 209).

\section{METODE PENELITIAN}

Dengan menerapkan konsep teoretis dari Girard, metode yang digunakan dalam penelitian ini ialah kualitatif-interpretatif yang telah lazim dipergunakan dalam penelitian teks-teks sastra. Dengan cara simak-catat, data yang terkumpul dideskripsikan, dianalisis, dan ditafsirkan secara komparatif dengan panduan teori yang diacu tersebut. Teknik content analysis digunakan dalam klasifikasi dan interpretasi data. Data primer yang dipakai adalah ketiga cerpen berjudul "Kuli Kontrak" karya Mochtar Lubis, "Tukang 
Cukur” karya Budi Darma, dan “Akhir Perjalanan Gozo Yoshimasu” karya Sori Siregar. Ketiga data didapatkan secara daring dari laman-laman seputar sastra Indonesia, yakni Agape: Media Pembelajaran Sastra Indonesia (http://goesprih.blogspot.com/2010/01/kuli-kontrak-mochtar-lubis.html) untuk cerpen Mochtar Lubis. Sementara itu, kedua cerpen lainnya diambil dari Cerpen Koran Minggu (https://lakonhidup.com/). Sejumlah artikel jurnal ilmiah, buku-buku referensi, dan pemberitaan di media mengenai pengarang, karya, dan dunianya yang gayut dengan tema kekejaman, balas dendam, dan pengambinghitaman dijadikan data sekunder.

\section{PEMBAHASAN}

Berikut adalah pembacaan ketiga cerpen dengan terang Teori René Girard. Pembahasan disajikan secara berurutan dari munculnya kekerasan, aksi balas dendam, lalu sangkutan kedua peristiwa, yaitu pengambinghitaman.

\section{Kekerasan}

Kekerasan lahir dari rahim persaingan atau rivalitas dalam memperebutkan sebuah objek. Objek tersebut sama-sama diinginkan oleh kedua pihak yang bersaing yang oleh Girard disebut hasrat mimesis. Dorongan untuk memperebutkan pelbagai keinginan membuat manusia bertindak kejam satu terhadap yang lainnya.

Objek hasrat dalam "Kuli Kontrak" adalah perempuan, dalam hal ini istri-istri para kuli pribumi. Terjadi persaingan antara kuli-kuli pribumi dan majikan mereka, yaitu opzichter Belanda. Cerpen "Kuli Kontrak” diterbitkan pertama kali di majalah Siasat Baru No. 650, Th. XIII, 25 November 1959 (Lubis, 2010). Mochtar Lubis menulis cerpen tersebut dengan konteks perlakuan sewenang-wenang Belanda terhadap kaum pribumi. Ketiga kuli disiksa oleh mandor penjara dengan cemeti panjang berwarna hitam yang "berhelak ke udara seperti ular hitam yang hendak menyambar, mengerikan” (Lubis, 2010: 4) untuk sebuah kesalahan yang bermuara dari pembelaan diri karena agitasi opzichter. Sepasang mata anak di bawah umur menjadi saksi kekerasan tersebut.

Dan terdengarlah bunyi membelah udara, mendengung tajam; lalu bunyi cemeti melanggar daging manusia, yang segera disusuli jeritan kuli kontrak yang di tengah melonjakkan kepalanya ke belakang. Dari mulutnya yang ternganga itu keluarlah suara jeritan yang belum pernah aku dengar dijeritkan manusia: melengking tajam membelah udara, menusuk seluruh hatiku, dan membuat tubuhku seketika lemah-lunglai. (Lubis, 2010: 4) 
Kekerasan, Balas Dendam, dan Pengambing Hitaman...

Di sini terjadi kekerasan beruntun. Pertama, opzichter Belanda terlebih dahulu melakukan kekerasan seksual terhadap istri para kuli. Kedua, suami-suami mereka kalap, lalu menyerang serta menikamnya. Ketiga, para kuli ditangkap dan dikenai hukuman cambuk yang kemungkinan besar akan berakhir dengan kematian karena mereka sudah tidak berdaya ketika menyerahkan diri. Lubis menulis, "Mereka tertangkap dalam hutan tidak jauh dari onderneming, separuh kelaparan dan kedinginan dan penuh ketakutan" (Lubis, 2010: 2). Sekarang makin terlihat bahwa kekerasan melahirkan kekerasan. Tepatlah pendapat Girard bahwa kekerasan itu menular (Sindhunata, 2006: 128).

Cerpen "Tukang Cukur" yang dimuat di Harian Kompas edisi 11 September 2016 merupakan salah satu dari puluhan karya Budi Darma yang berkisah tentang rivalitas. Objek yang membangkitkan hasrat tukang cukur adalah darah. Tokoh utama cerpen tersebut memperoleh kepuasan ketika melihat dan membuat orang lain terbunuh atau setidaknya terluka. Hasrat yang berbuntut kekerasan pada mulanya dapat dilakukan dengan mudah ketika si tukang cukur melukai kepala beberapa pelanggannya. Seperti biasanya, dia akan meminta maaf sambil berdalih bahwa kecelakaan "kecil" itu dia lakukan tanpa sengaja.

Kekerasan berlanjut ketika tukang cukur bergabung dengan sebuah kelompok bersenjata. Rivalitas mulai muncul ketika seseorang berhadapan dengan pihak yang berseberangan. Karena kekerasan itu, menurut Girard, menular, tukang cukur pun terjangkiti. Tokoh tersebut makin haus darah seiring pergantian kekuasaan dari satu kelompok ke kelompok lain yang terlibat dalam konflik. Kekerasan tokoh ketika menjadi pengikut PKI digambarkan sebagai berikut.

Gito menyaksikan, orang-orang yang diikat tangannya digertak-gertak oleh tukang cukur dan temantemannya, disuruh berdiri rapi, kemudian diberondong dengan serangkaian tembakan. (Darma, 2016)

Kekerasan terus berlangsung dengan hasrat sama, yakni darah, tetapi agen rivalitasnya berbeda. Tukang cukur menjadi kaki tangan pasukan Siliwangi. Sekarang rivalnya adalah orang-orang PKI yang dahulu menjadi kawan seperjuangannya. Anggota dan simpatisan PKI serta pemimpinnya ditangkap. Mereka diarak ke alun-alun kota untuk ditembak di bawah pohon beringin. Mata anak kecil yang sama menjadi saksi kekerasan itu.

Gito datang dan melihat pemandangan yang sukar dipercaya: tukang cukur, berpakaian preman, tidak lagi memakai pakaian tentara PKI, memberi komando kepada orang-orang yang akan dihukum mati untuk berdiri dengan tegap dan rapi, kemudian melilitkan kain ke wajah-wajah mereka supaya mereka tidak bisa melihat regu penembak. (Darma, 2016) 
Peralihan kekuasaan di antara pihak-pihak yang terlibat konflik makin melanggengkan kekerasan. Keinginan tukang cukur untuk berkuasa dan menewaskan orang makin kuat. Rivalitas makin sengit sepanjang lintasan sejarah yang dialaminya dari perang sipil PKI-TNI, agresi militer Belanda, hingga hengkangnya tentara KNIL dari Indonesia. Nafsu tukang cukur untuk mengucurkan darah musuh terhenti dengan gugurnya tokoh tersebut sebagai pejuang kelompok subversif NII. Tokoh tukang cukur dengan hasrat membunuhnya menambah deretan tokoh-tokoh ganjil yang sering dijumpai dalam karyakarya Budi Darma. Selain efek absurditas, tokoh-tokoh itu sengaja diciptakan oleh sang pengarang untuk menghadirkan dunia lisan yang sarat dengan hiperbola ke dalam tulisan (Siswanto, 2010: 60).

Kekerasan dalam cerpen Sori Siregar yang terbit di Harian Kompas 16 Juli 2017, “Akhir Perjalanan Gozo Yoshimasu”, dimulai dengan datangnya segerombolan pemuda ke markas tentara Jepang di kota Tebing Tinggi, Sumatra Utara. Kekerasan verbal digambarkan sebagai berikut.

"Serahkan sekarang juga," ujar lelaki besar itu. "Jika tidak, kami akan menyerbu masuk dan korban akan berjatuhan di pihak tuan. Tuan lihat betapa banyaknya pemuda di belakang saya." (Siregar, 2017)

Kekerasan fisik selanjutnya ditunjukkan oleh para pemuda yang bertindak sendiri tanpa menghiraukan perintah sang pemimpin, lelaki bertubuh besar itu. Pemuda-pemuda berbambu runcing membantai seluruh tentara Jepang di markas itu setelah senjata mereka dilucuti. Kekerasan itulah yang terus-menerus menghantui ingatan laki-laki yang bertubuh besar. Berikut adalah penggambarannya.

Dua puluh tahun kemudian, kekejaman yang serupa terjadi di negeri ini. Anak lelaki bertubuh besar juga gagal mencegah kekejaman teman-temannya. la tidak dapat berbuat apa-apa ketika para anggota ormas yang dipimpinnya membantai puluhan orang yang belum tentu bersalah akibat gejolak politik yang tidak diinginkan. (Siregar, 2017)

Tidak seperti kedua cerpen sebelumnya, si pencerita dalam cerpen Siregar tidak hanya mengamati terjadinya kekerasan, tetapi juga turut mengambil bagian dalam kekerasan itu yang sungguh disesalinya. Kekerasan serupa disaksikan pula oleh anaknya yang juga tidak berhasil mencegah tindakan anarkistis rekan-rekan kerjanya. Di sini terlihat bahwa selain menular, kekerasan juga menurun kepada generasi berikutnya. 
Kekerasan, Balas Dendam, dan Pengambing Hitaman...

\section{Balas Dendam}

Girard membedakan antara imitasi dan mimesis. Imitasi biasanya dipahami sebagai aspek positif ketika seseorang mereproduksi perilaku orang lain, sedangkan mimesis menyiratkan aspek negatif dari sebuah persaingan (Andrade). Persaingan atau rivalitas terus berlanjut ketika pihak-pihak terkait melakukan balas dendam. Balas dendam, seperti kekerasan, juga menular.

Tema balas dendam dalam "Kuli Kontrak" cukup sederhana: aparat pemerintah Belanda menghukum cambuk tiga orang kuli kontrak yang menghalangi pelecehan terhadap istri-istri mereka. Ketiga kuli pribumi itu dijatuhi hukuman, tetapi juga sekaligus dijadikan korban balas dendam meskipun keduanya dibedakan oleh motivasi dan tujuan. Balas dendam dimaksudkan untuk membuat pelanggar menderita, sedangkan hukuman berfungsi untuk mencegah agar pelanggar tidak berperilaku buruk lagi pada masa depan. Namun, dalam cerpen Lubis ini masa depan bagi ketiga pelanggar sudah tidak ada lagi. Sebelum perkaranya dibawa ke depan hakim, mereka dilecuti karena telah menyerang sang opzichter Belanda. Ketiganya mungkin akan mati setelah dicambuk habis-habisan. Jadi, hukuman yang mereka terima adalah balas dendam yang diformalkan oleh pemerintah kolonial.

Sebaliknya, balas dendam dalam cerpen Budi Darma sedikit lebih kompleks karena melibatkan beberapa pihak yang berganti peran dari waktu ke waktu. Salah satu aksi balas dendam dinarasikan secara langsung sebagai berikut.

Kabar tidak jelas beredar, pada suatu hari tukang cukur itu dihajar oleh tentara Siliwangi, dengan tuduhan, dia membuat daftar orang-orang yang dibencinya untuk dihukum mati, tanpa bukti. (Darma, 2016)

Seperti karya Budi Darma yang lain, teknik surprise ending dipergunakan untuk menggarisbawahi tema balas dendam ini.

Ketika Gito tiba di bekas pabrik rokok, sudah banyak orang berkerumun di sana. Semua mayat tentara yang terjebak di pabrik sudah diangkut keluar, dibaringkan di pinggir jalan. Salah satu mayat itu tidak lain dan tidak bukan adalah tukang cukur. (Darma, 2016)

Aksi balas dendam dalam cerpen "Akhir Perjalanan Gozo Yoshimasu” lebih bersifat komunal dibandingkan dengan balas dendam pribadi seperti pada kedua cerpen sebelumnya. Di dalam cerpen tersebut dilukiskan betapa pemuda-pemuda berbambu runcing sudah tidak sabar lagi. Mereka hendak melampiaskan dendam sebagai bangsa terjajah ketika menemui kapten Jepang itu. 
Semua pemuda yang berada di depannya juga diam. Rasa takut belum meninggalkan wajah mereka. Susah rasanya melepaskan diri dari rasa takut, benci, dan amarah setelah lebih dari tiga tahun ditindas oleh tentara-tentara bermata sipit itu. Tentara Jepang dikenal kejam dan gemar menyiksa. (Siregar, 2017)

Pemuda-pemuda tersebut menjadi gelap mata dan emosional. Mereka ingin segera melampiaskan hasrat membalas dendam. Mereka tidak mampu berpikir jernih sehingga menganggap semua tentara Jepang "kejam dan gemar menyiksa". Karena itu, ketika pemudapemuda itu ganti menyiksa dan menghabisi tentara-tentara Jepang yang tak melawan itu, dendam komunal mereka terasa terbalaskan.

Kompleksitas terlihat di sini karena lelaki bertubuh besar tidak menghendaki balas dendam sebesar yang dirasakan oleh anak buahnya. Ketika seorang pemuda dengan marah merampas senapan dari tangan temannya dan mengarahkan senjata tersebut ke tubuh Yoshimasu yang tidak berdaya, lelaki bertubuh besar menghalanginya. Tokoh bertubuh besar, dengan cara pandang Girard, tidak terkecoh oleh hasrat tiruan. Hal itu terlihat dalam adegan yang dikutip agak panjang demi kejelasan sebagai berikut.

Lelaki bertubuh besar berteriak mencegahnya.

Dengan sekuat tenaga, pemuda pemilik bambu runcing itu menusukkan sangkur yang melekat di senapan itu ke dada Yoshimasu.

Perwira Jepang itu bersimbah darah.

Lelaki bertubuh besar itu mencoba menolong Yoshimasu.

Tapi, saat itu juga sangkur yang masih merah dengan darah itu diarahkan sang pemuda ke dada lelaki bertubuh besar itu.

Jika salah bersikap, ia akan mengalami nasib seperti Yoshimasu. (Siregar, 2017)

Karena hasratnya tidak sama dengan pemuda-pemuda yang diamuk amarah, lelaki bertubuh besar itu tidak termobilisasi untuk membalas dendam. Siregar menegaskannya demikian: "Setelah itu lelaki bertubuh besar hanya dapat menyaksikan dengan rasa tidak percaya semua yang dilakukan para pemuda yang tadi dipimpinnya." (Siregar, 2017)

Dengan demikian, dapat disimpulkan bahwa pembedaan yang dilakukan Girard atas imitasi dan mimesis seperti yang disebutkan pada awal subbab ini terwakili oleh beberapa tokoh dalam cerpen-cerpen yang dikaji. Ayah dalam "Kuli Kontrak" dan lelaki bertubuh besar dalam "Akhir Perjalanan Gozo Yoshimasu" memproduksi perilaku positif (imitasi) setelah menyaksikan aksi kekerasan. Keduanya menolak dan mengutuki tindakan balas dendam. Sementara itu, hasrat mimesis yang mempertuan dan melahirkan balas dendam terlihat pada sebagian besar tokoh. Yang masuk dalam kelompok ini, antara lain, ialah para pemuda yang kalap dan rekan-rekan seorganisasi anak laki-laki yang bertubuh besar dalam cerpen Siregar; kuli kontrak dan opzichter Belanda dalam cerpen Lubis; dan hampir semua tokoh dalam cerpen Budi 
Kekerasan, Balas Dendam, dan Pengambing Hitaman...

Darma. Tokoh-tokoh bocah yang bertindak sebagai narator tidak masuk dalam kelompok tersebut karena mereka hanya mengamati.

\section{Pengambinghitaman}

Kekerasan adalah lingkaran setan yang terus-menerus dan menimbulkan balas dendam (Sindhunata, 2006: 207). Lingkaran setan itu harus diputus. Girard menyebutnya "pengambinghitaman", yakni proses yang merujuk pada ritual keagamaan kuno saat dosadosa manusia secara metaforis dikenakan pada seekor kambing. Lalu, binatang kurban tersebut ditinggalkan di padang pasir atau dikorbankan untuk para dewa (Andrade). Berangkat dari ritual semacam itu, orang yang menerima kekerasan komunal disebut "kambing hitam". Kematiannya diperlukan bagi sebuah regenerasi perdamaian komunal dan pemulihan hubungan.

Ketiga kuli kontrak yang dihukum cambuk, orang-orang sipil dan militer yang dibunuh atas inisiatif tukang cukur, dan Kapten Gozo Yoshimasu adalah kambing hitam. Mereka dikorbankan agar rivalitas tidak berlanjut dengan balas dendam.

Pada cerpen Mochtar Lubis, kuli-kuli kontrak harus dihukum agar tidak terjadi konflik berkelanjutan di onderneming Kayu Aro di daerah Jambi antara pekerja-pekerja pribumi dan pengawas kebun berkebangsaan Belanda. Peristiwa pencambukan di penjara yang diam-diam disaksikan oleh si pencerita merupakan sebuah ritus korban.

Sebagai seorang demang atau wedana, ayah si pencerita harus menjadi penengah yang membela kepentingan penjajah meskipun berlawanan dengan hati kecilnya. Dalam posisinya sebagai pegawai pemerintah kolonial, tokoh Ayah ini dapat dikatakan telah berperan serta dalam ritus korban tersebut. Itulah mengapa ia berpesan kepada anaknya seperti berikut: "Jika engkau besar, jangan sekali-kali kau jadi pegawai negeri. Jadi pamong praja! Mengerti?” (Lubis, 2010: 7).

Akan tetapi, ayahnya juga pernah menjadi semacam kambing hitam ketika dua kampung berhenti berperang setelah sebuah batu menyasar mengenai helmnya. Kepalakepala kampung itu meminta maaf seraya berkata bahwa mereka tidak bermaksud memerangi sang wedana. Mereka dengan cepat menerima usulnya untuk berdamai dan saling berbagi dalam pengairan dan pengolahan sawah. Dalam hal ini, meskipun ada korban yang kemudian menciptakan perdamaian, mekanisme ritusnya tidak didasari oleh aksi balas dendam. 
Sementara itu, dalam cerpen "Tukang Cukur" mekanisme kambing hitam digambarkan sebagai berikut.

Kabar tidak jelas beredar, pada suatu hari tukang cukur itu dihajar oleh tentara Siliwangi, dengan tuduhan, dia membuat daftar orang-orang yang dibencinya untuk dihukum mati, tanpa bukti.

Pengambinghitaman terlihat paling jelas dalam cerpen "Akhir Perjalanan Gozo Yoshimasu", yaitu kapten Jepang dijadikan tumbal untuk mengakhiri kekerasan. Ironisnya, kekerasan tidak berkurang, tetapi justru menjadi-jadi.

Dapat ditegaskan di sini bahwa kambing hitam yang sejati adalah Gozo Yoshimasu, kapten Jepang yang "dikenal lembut menghadapi siapa saja", bukan "prototipe tentara pendudukan yang terkenal garang dan tanpa belas kasihan" (Siregar, 2017). Profil Yoshimasu ini cocok dengan gambaran Girard tentang kambing hitam, yaitu seorang pribadi yang luar biasa yang "tak terkenai wabah kekerasan" (dalam Sindhunata, 2006: 270).

Yoshimasu tidak menginginkan adanya kekerasan sehingga berusaha mengatasi kekerasan itu. Kapten yang halus, tetapi tegas ini meyadari bahwa para pemuda yang terbakar semangat dan amarah itu amat memerlukan persenjataan untuk mempertahankan kemerdekaan. Perwira Jepang tersebut mengambil risiko dihukum oleh tentara Sekutu karena dianggap bersekongkol untuk menjadikan Indonesia merdeka. Yoshimasu tidak menginginkan pertumpahan darah. Dia lalu membiarkan para pemuda mengambil semua senjata. Oleh karena itu, ketika salah seorang pemuda yang tidak menghiraukan perintah laki-laki bertubuh besar menusukkan sangkur ke tubuh Yoshimasu, terbuktilah kata Girard bahwa ketika orang tidak melawan, rezim kekerasan menutup mulutnya. Siregar menggambarkan ritus itu dengan lugas: "Setelah mengerang beberapa saat, tubuh Yoshimasu tidak lagi bergerak dan darah terus mengucur dari tubuhnya" (Siregar, 2017). Pada akhir perjalanan, Gozo Yoshimashu tidak melawan. Dia berhasil membungkam kekerasan. Dia rela berkorban. Dialah kambing hitam.

\section{SIMPULAN}

Telah dibahas dalam penelitian ini bagaimana kekerasan, balas dendam, dan pengambinghitaman dalam tiga cerpen Indonesia modern, yakni "Kuli Kontrak", "Tukang Cukur", dan "Akhir Perjalanan Gozo Yoshimasu" menjadi tema-tema pokok yang mengikat satu sama lain. 
Kekerasan, Balas Dendam, dan Pengambing Hitaman...

Telah ditunjukkan pula dalam kajian ini bahwa kekerasan sebagai buntut hasrat mimesis terwakili dalam ketiga cerpen tersebut. Kekerasan ditunjukkan di antara sesama individu (kuli kontrak melawan opzichter Belanda), individu terhadap kelompok (tukang cukur melawan pejuang sipil dan militer), dan kelompok terhadap individu (pemudapemuda berbambu runcing melawan Gozo Yoshimasu). Akan tetapi, karena watak mimesisnya, kekerasan biasanya menular dan menyebar.

Selanjutnya, telah dibahas pula aksi balas dendam yang merupakan dampak langsung rivalitas atas nama perempuan (dalam "Kuli Kontrak"), darah (dalam "Tukang Cukur”), dan kekuasaan (dalam “Akhir Perjalanan Gozo Yoshimasu”). Ketiga objek yang diperebutkan itu dekat satu dengan yang lainnya. Yang paling korosif dari ketiganya adalah kekuasaan karena hasrat itu tampak di ketiga cerpen dengan tingkat yang berbedabeda.

Simpulan terakhir adalah mekanisme kambing hitam ditemukan dalam ketiga cerpen dengan asal-muasal dan implikasi yang berbeda-beda. Persamaannya adalah kambing hitam biasanya mewujud dalam tokoh-tokoh yang termarginalkan/terkalahkan. Mereka adalah para kuli kontrak, korban kesadisan tukang cukur, dan Gozo Yoshimasu. Temuan itu mengafirmasi gagasan Girard bahwa kambing hitam biasanya kelompok yang terpinggirkan, tetapi disakralkan dalam ritus korban karena mereka berpotensi memutus rantai kekerasan sehingga membawa perdamaian.

Akhir kata, jalinan antara kekerasan, balas dendam, dan pengambinghitaman yang selalu didaur ulang dalam karya sastra lintas negara perlu terus-menerus diteliti dan direfleksikan. Selama manusia memiliki hasrat, ketiganya akan terus ada. Karya sastra berfungsi untuk menangisi dan mengingatkan manusia yang silap dan batil agar hasrat manusia bisa dikelola dengan lebih baik.

\section{DAFTAR PUSTAKA}

Abshire, W. E. (2010). Violence and the sacred: Interpretations of René Girard in Christian philosophy and peace studies. Annales Philosophici, 1(1), 5-9. https://philpapers.org/rec/ABSVAT

Alimun, A. A. (2014). Patriotisme Tokoh dalam Novel Jalan Tak Ada Ujung Karya Muchtar Lubis (Doctoral dissertation, Universitas Negeri Gorontalo). http://repository.ung.ac.id/skripsi/show/311409138/patriotisme-tokoh-dalam-novel-jalan-tak-ada-ujung-karyamuchtar-lubis.html

Andayani, A., \& Jupriono, D. (2018). Comparative Literary Study on Mochtar Lubis'harimau Harimau and Herman Melville's Moby Dick. PARAFRASE: Jurnal Kajian Kebahasaan \& Kesastraan, 18(2), 63-71. https://doi.org/10.30996/parafrase.v18i01.1381 
Andrade, G. (n.d.). René Girard (1923-2015). Retrieved September 27, 2019, from Internet Encyclopedia of Philosophy: https://www.iep.utm.edu/girard/\#H2

Dewi, N. (2019). Positioning the Chinese Princess of Peace in World Literature. JP-BSI (Jurnal $\begin{array}{lllll}\text { Pendidikan Bahasa dan } & \text { Sastra Indonesia), }\end{array}$ https://journal.stkipsingkawang.ac.id/index.php/JP-BSI/article/view/905.Darma， B. (2016, September 11). Tukang Cukur. Retrieved Mei 15, 2019, from Cerpen Koran Minggu. https://doi.org/10.26737/jp-bsi.v4i1.905

Ferdinal, McCredden, L., Coté, J., \& Clark, M. (2013). Abuse of power, oppression and the struggle for human rights in modern indonesian short fiction (No. Doctor of Philosophy) Deakin University. dro.deakin.edu.au > eserv > ferdinal-abuse-2014A

Girard, R. (1986). The Scapegoat, trans. Yvonne Freccero. Baltimore, MD: Johns Hopkins University Press.

Lubis, M. (2010). Kuli Kontrak. Retrieved July 25, 2019, from Agape: Media Pembelajaran Sastra Indonesia: http://goesprih.blogspot.com/2010/01/kuli-kontrak-mochtar-lubis.html

Nurfadila, U. (2018). Pemberontakan Tokoh Absurd pada Kumpulan Cerpen Hotel Tua karya Budi Darma (Doctoral dissertation, University of Muhammadiyah Malang). https://www.semanticscholar.org/paper/PEMBERONTAKAN-TOKOH-ABSURD-PADAKUMPULAN-CERPEN-TUA-Nurfadila/4f06b04b5df220839ab7bee70705ae7d38eed561

Prasetyo, Y., \& Haryadi, H. (2017). Kekerasan terhadap Tokoh Perempuan dalam Novel Seperti Dendam Rindu Harus Dibayar Tuntas dan Lelaki Harimau Karya Eka Kurniawan. Seloka: Jurnal Pendidikan Bahasa dan Sastra Indonesia, 6(2), 152-160 https://journal.unnes.ac.id/sju/index.php/seloka/article/view/17279.

Purnawijayanti, F. (2006). Pride and Authenticity in "One Hundred Years of Solitude" and "Anak Bajang Menggiring Angin". Unpublished Graduate Thesis. Sanata Dharma University, Yogyakarta.

Schwager, R. (2000). Must there be Scapegoats?: Violence and Redemption in the Bible. Herefordshire: Gracewing Publishing. https://trove.nla.gov.au/work/11890978?selectedversion=NBD24096627

Sindhunata. (2006). Kambing Hitam: Teori René Girard. Jakarta: Gramedia Pustaka Utama.

Siregar, S. (2017, Juli 16). Cerpen Koran Minggu. Retrieved Juni 27, 2019, from Akhir Perjalanan Gozo Yoshimasu: https:/lakonhidup.com/2017/07/16/akhir-perjalanan-gozo-yoshimasu/

Siswanto, W. (2010). Tokoh Ganjil dalam Karya Sastra Budi Darma. Jurnal Humaniora, 22(1), $52-$

63. https://media.neliti.com/media/publications/12011-ID-tokoh-ganjil-dalam-karya-sastrabudi-darma.pdf.

Suprapto, S. (2019). Kepribadian Tokoh dalam Novel Jalan Tak Ada Ujung Karya Muchtar Lubis: Kajian Psikoanalisis Sigmund Freud. METAFORA, 5(1), 54-69 http://jurnalnasional.ump.ac.id/index.php/METAFORA/article/view/5028.

Suwondo, T. (2010). Mencari Jati Diri: Kajian atas Kumpulan Cerpen Orang-Orang Bloomington Budi Darma. Yogyakarta: Elmatera Publishing. https://www.scribd.com/document318071596/Mencari-Jati-Diri-Kajian-Cerpen-Orang-Orang-Bloomington-Budi-Darma

Thahar, H. E. (2008). Kekerasan Cerpen-Cerpen Indonesia dalam Akhbar Harian Kompas (19921999): Suatu Tinjauan Struktural Genetik. JATI - Journal of Southeast Asian Studies, 13, 127-146. https://jati.um.edu.my/article/view/6204. 